\title{
Educational Reform of University Mathematics
}

\author{
Yuping Qin ${ }^{1}$, Shuang Zhang ${ }^{1,2}$ and Yihe Liü $^{2 *}$ \\ ${ }^{1}$ The Engineering \& Technical College of Chengdu University of Technology, Leshan, 614000, P.R. \\ China \\ ${ }^{2}$ College of computer science, Neijiang Normal University, Neijiang, 641000, P.R. China \\ zhangshuanghua1@126.com; qingyuping520025@126.com, liu_yihe@163.com \\ *The corresponding author
}

Keywords: University mathematics; Educational reform; Innovation ability; Comprehensive quality

\begin{abstract}
University mathematics plays an important role in improving undergraduates' mathematical quality, comprehensive quality and innovative awareness and ability. The cramming education phenomenon prevails in university mathematics teaching and educational thought lags; the teaching methods are outmoded, short of change; the teaching objective is single and lacks of hierarchy. This not only cannot adapt to different departments and needs of different training objectives, but also goes against individualized teaching and growth of the talents. Improving the comprehensive quality of university mathematics teachers, reforming teaching concept, teaching methods and means of university mathematics, strengthening the cultural value education of university mathematics are beneficial to cultivate high-quality innovative talents and comprehensively improve the teaching quality of university mathematics.
\end{abstract}

\section{Introduction}

University mathematics is an important basic theoretical course of all majors' training program in colleges and universities; it is very important for students to successfully complete undergraduate education, and it is also irreplaceable for cultivation of students' quality and ability; so it is an important index of guaranteeing university talent cultivation quality. On the one hand, students' basic mathematical quality is cultivated by teaching systematic mathematics knowledge; on the other hand, common mathematical methods are taught to cultivate students' ability to creatively apply mathematics to deal with practical problems. By learning university mathematics, on the one hand, students can lay a good foundation for learning other courses; on the other hand, it can improve their logical thinking ability and innovation ability. University mathematics plays an important role in improving the students' mathematics quality and comprehensive quality, inspire their innovation consciousness and cultivate their innovative ability. Reform of teaching concept, teaching methods and means of university mathematics is helpful to cultivate high-quality innovative talents; therefore, improving teaching quality of university mathematics has always attracted extensive attention; it is associated with higher mathematics teaching reform and the study on how to improve the teaching quality of higher mathematics course; and it is related to research on the educational function of mathematical culture. By studying these references, I put forward the following questions.

\section{Current Teaching Status of University Mathematics}

(1) Lagging mathematics educational thought. Improving students' mathematical thinking ability and mathematics application consciousness is one of the basic objectives of mathematics education; while the current mathematics education pays more attention to knowledge teaching and mastery of mathematics knowledge.

(2) Ignoring the role of mathematics in the innovation education. Mathematics is one of the most 
innovative subjects in human cultural creation; developing the innovation function of mathematics is one of the main tasks of the mathematics education. However, over many years, in university mathematics education, main attention has been paid to the knowledge property of mathematics, but its innovation function has always been ignored.

(3) Individualized teaching should be improved soon. At present, higher education has developed from the elite education stage to the popular education stage; in the same major, students' knowledge structures and learning abilities differ greatly; so attention should be paid to different needs of students and their personality development, so as to change the original teaching mode at the elite education stage.

(4) Outmoded teaching methods and single teaching mode. The traditional teaching method is to teach with chalk and blackboard, and teachers teach mathematics theory knowledge based on the book content only, from concept explanation to theorem proving and then to examples and exercises; the cramming teaching method is not beneficial to cultivation of students' mathematics quality and creative thinking.

(5) Cultural function of mathematics cannot be fully exerted. Mathematics has its own unique thinking way and unique expression form; it has important cultural value as well as literature and art. Traditional university mathematics education has ignored mathematical culture and its education function; this method deviates from the purpose of mathematics education.

(6) The importance of the course conflicts with reduction in class hours of the course. For undergraduate education, the basic practice ability and self-learning ability should be emphasized even more; in the basic theoretical knowledge, mathematics should be naturally put in the important position. At present, most colleges and universities reduce class hours of the common basic courses in the case of the total hours reduced gradually, especially math courses; in order to adapt to the demand of less class hour teaching, some theoretical proving has been cut in teaching, they are inducted and proved in the form of examples, thus training of theoretical research is greatly weakened. this not only causes great difficulties for students to learn subsequent courses, the quality education' goals of mathematics courses also turns into empty talk.

\section{Improving Teachers' Comprehensive Quality and Reforming Existing Teaching Modes}

According to the above situations, to comprehensively improve teaching quality of university mathematics, enhance students' comprehensive quality and adapt to social needs, the university teaching reform is extremely urgent.

Improving Teachers' Comprehensive Quality and Strengthening Teaching Team Construction. Teachers are key for teaching and educational reform. A dedicated teaching team with higher professional skill is significant to successfully reform university mathematics teaching. To renew teachers' education idea, improve their teaching level and scientific research ability, and enhance their comprehensive application ability and comprehensive quality are the fundamental approach and guarantee of university mathematics teaching reform. If teachers lack of profound understanding of teaching content, no matter which teaching methods are used, it will not achieve good teaching effect; therefore, teachers must have profound mathematics and related knowledge, master advanced and flexible teaching methods, enable students not only to learn systematic mathematics knowledge, also to master mathematics thoughts and methods, improve the application ability to analyze and solve problems, so as to achieve outstanding teaching effect.

As one important task of teaching quality engineering construction, teaching team construction is effective to integrate teaching resources and promote teaching reform. Strengthening teaching team construction plays a key role in strengthening quality awareness, deepening teaching reform, promoting education innovation, standardizing teaching management, improving teaching quality, promoting major construction and course construction and cultivating innovative talents. Teachers teaching the same course are organized to form a teaching team according to different ages and different titles. Professors and doctoral student supervisors should give full play to helping and leading 
young and middle-aged teachers and complement each other. Ethics education should also be strengthened to make each teacher really combine teaching with education.

Improvement of Teaching Methods, Modes and Means is Fundamental for Teaching Reform. In our country, because of the effect of the traditional exam-oriented education mode and the former Soviet Union's educational mode, the duck-stuffing cramming education including concept definition, theorem inference and example calculation prevails in university mathematics teaching. The teaching method becomes a teacher-centered cramming teaching method in which teaching is emphasized but learning is neglected. With the development of multimedia equipment, the computer become the main teaching tool of teachers and the PPT becomes teaching plans of teachers; but the teaching methods are outmoded and lack of change; the teaching targets are unified but lack of hierarchy. Therefore, they not only cannot adapt to needs of different departments and training goals, are also not beneficial to individualized teaching and growth of talents, so they need to be practically improved.

Flexible Teaching Methods Used to Cultivate Students' Innovative Spirit. Teaching methods are varied, but they have only one purpose; it is to cultivate students' ability to find, analyze and solve problems, to cultivate their innovation consciousness and innovation ability and to cultivate their continuous learning ability as they accept knowledge. In the teaching process, the research-oriented, exploratory, discussion-oriented and heuristic teaching methods which are helpful to cultivate students' autonomous learning ability should be actively adopted; the programmatic tedious teaching mode including definition, theorem, examples and exercises should be changed; besides, the heuristic and discussion-oriented teaching should be strengthened; mathematical concepts should be introduced from the actual problems; attention should be paid to introduce of practical problems and their intuitive properties; the research methods from specific to general and from general to specific should be emphasized; attention should be paid to induction of special problems and application of general problems as well as application of mathematics; students' comprehensive quality should be cultivated; in teaching, the interactive teaching method should be used between teachers and students; some enlightening questions should be put forward to guide students to find, analyze and solve problems. On the basis of the specific content of the course, the case-based teaching with some additional practical problems is used to enhance learning interest; some actual problems are specified as after-class homework, and the students are allowed to choose freely according to their own interest and discuss with each other; in addition, the research-oriented exploratory practice may be tried to cultivate students' innovative spirit.

Graded Teaching Used to Explore New Teaching Mode. Along with the continuous expansion of institutions of higher education in enrollment scale, our country's higher education has entered the popularized education stage from the elite education stage. It is characterized by diversification and multiple standards; demands for talents differ greatly due to the social development; the single quality standard formed from the traditional elite education has not adapt to the popularized higher education; in teaching of university mathematics, all students with the same major are taught in accordance with the unified teaching plan, the unified teaching requirement, the unified training specifications and teaching mode, while their individual differences are ignored; however, students' development directions differ from each other and they have different special features; if they are cultivated as per the same requirement, specification and teaching mode, it is not beneficial to personality development of talents, and it may obstruct all kinds of talents rich in innovation spirit from standing out. Therefore, the graded teaching is an effective way to implement innovation education and cultivate innovative talents.

The graded teaching refers to teaching the students with the same grade and major in separate classes according to students' basis and ability; each teaching class has different teaching contents and requirements, but the basic requirements achieved finally are same. However, the highest development goals may be different, so as to exert students' individual potential.

The graded teaching method is detailed as follows: after students are enrolled, the placement test of mathematics is organized by each faculty. According to the test scores, the total college entrance 
examination score and the math score as well as their own wills, the students with the same major are divided into Class A (40\%) and Class B (60\%). The basic teaching requirements are properly adjusted based on the teaching program issued by the Ministry of Education, and the teaching programs and the teaching plans of Class A and Class B are prepared respectively. The students in Class A are taught as per the enhanced basic integrated application, so as to cultivate students to have higher mathematical quality and get the ability to solve problems with mathematics; besides, the mathematical modeling thought is also integrated in the course to train their innovation consciousness and lay a solid foundation for postgraduate entrance examination; the students in Class B are taught as per the basic integrated application to cultivate their learning ability and get the ability to analyze and solve problems as well as a certain innovation ability, so as to lay a foundation for the following specialized courses. All the students in Class A and Class B can obtain their own credits after they complete all courses; because the students in different levels may obtain different credits after they pass the examination, they may be tested according to different requirements.

The graded teaching can fully arouse the learning initiative of the students at all levels, maximize their self-regulation of learning, develop their mathematics potential and cultivate interest in mathematics, so as to really achieve individualized teaching based on the basic teaching requirements. Therefore it is a positive measure to improve the teaching quality of university mathematics.

Organic Integration of Modern Education Technology and University Mathematics Teaching. With the rapid development of science and technology, the modern education technologies have been widely used in the teaching process. Use of modern education technologies provide students with the most direct all-dimensional multi-channel audio and visual perception. This is inevitable development trend of the higher education. In the mathematical reasoning process of proving mathematical theorem, its advantage is especially obvious. But in this teaching mode, some contents are difficult for students to understand, for example, in teaching of space analytic geometry and double integral, construction of spatial curved surface, shapes of three-dimensional body enclosed by multiple surfaces and the boundary surfaces, and so forth; it will directly affect learning of the space analytic geometry, the multiple integral and the subsequent course.

At present, in teaching the university mathematics, plenty of teaching content conflicts with less class hours, so the teaching efficiency must be improved in order to complete the teaching task required in the teaching program. The educational information technology builds an open networked multimedia interactive dynamic learning environment for university mathematics teaching. In the teaching process, the realistic problem scenario can be created with the computer, so as to visualize the abstract problems, turn the static images into dynamic frames, improve vitality and enjoyment of mathematics learning, stimulate students' learning initiative and enhance the teaching effect. Organic combination of modern education technologies and university mathematics teaching, and scientific and reasonable use of modern education technologies are the important ways to improve classroom teaching efficiency and comprehensively enhance the teaching quality of university mathematics.

Strengthening cultural value education of mathematics

In the traditional mathematical education, logicality, science and completeness of disciplines knowledge are emphasized and attention is paid to knowledge infusion only; while teachers are not unaware to offer education of mathematical thought spirit and cultural character to students by imparting knowledge. Great importance is attached to only the scientific value of mathematics, while no attention is paid to thinking development and ability cultivation; Only formal training is emphasized, while no attention is paid to promotion of practical application and cultural spirit.

Strengthening mathematical culture education can improve college students' interest of learning mathematics, develop the confidence in learning mathematics, form persevering spirit and scientific attitude, gradually understand science value, application value and cultural value of mathematics, form a critical thinking habit and advocate rational spirit of mathematics; this is beneficial to improvement of the college students' innovation consciousness. Rendered mathematical spirit thought and method of mathematics culture in mathematics science are indispensable to cultivate people's lofty sentiment and improve psychological quality. The purpose of learning mathematics not only is to acquire 
mathematical knowledge, above all, it is to feel the spirit of mathematical thought spirit and methods, improve thinking ability and cultivate volitional quality; furthermore, it is to carry forward mathematics spirit in many fields such as study, work and life. Besides, it is conducive to improvement of college students' personality.

Mathematical beauty is important content of mathematical culture; mathematical beauty is mainly manifested in symmetrical beauty, simple beauty, unified beauty, harmonious beauty, strange beauty, and other aspects; the value of university mathematics aesthetic education is to edify students' sentiment, arouse their learning interest, and guide them work actively, devote themselves to science and cultivate their appreciation ability of beauty; this is helpful to improve their thinking quality.

University mathematics have influence on college students' cultural quality. Mathematics education is an important means of quality education; it may become the tool used to edify sentiment, pursue truth and enlighten mind. Connotations of university mathematics knowledge such as cultural value, are indispensable important content in the mathematics course and are the intrinsic inevitable requirement of mathematics quality education. Penetrating mathematics culture in mathematics teaching is the basic requirement for achieving mathematics quality education. Teachers should attach importance to relation between mathematics and other subjects in the teaching process, emphasize combining theory with practice, properly lower the requirements for mathematical knowledge, mathematical skills, mathematical calculation; furthermore, teachers should pay attention to improvement of mathematical methods, mathematical thought and mathematical concepts, understanding and application of knowledge, so as to integrate mathematical culture into the teaching process really. To improve teaching quality and college students' comprehensive quality, cultural value education of mathematics must be strengthened.

Teaching reform of university mathematics is an eternal topic and a long-term project. How to improve teaching quality and teaching effect of university mathematics is an issue needing constant discussion. In the teaching process of university mathematics, the teaching methods should be continuously improved to stimulate students' learning interest and innovation spirit, cultivate their mathematical thinking ability and application ability, so as to improve the teaching quality of university mathematics greatly.

\section{References}

[1] LiXiaoli. Discussion of Teaching Diverse Teaching Methods of Probability and Statistics [J]. University Mathematics, 2005, 21(4): 33-35

[2] SunFengqi. Discussion on Teaching Reform of Higher Mathematics [J]. Journal of Jilin normal university, 2005(1):109-110

[3] LinZhengyan. Some Suggestions of Curriculum Reform of Probability and Statistics [J]. Studies In College Mathematics, 2001, 4(1):6, 30

[4] LiePuyan. Education and Teaching Reform of Higher Mathematics [J]. Sun Yatsen University Forum, 2005, 25(3):12-14

[5] ShiQingsheng. Teaching Reform and Practice of Probability and Mathematical Statistics Course [J]. Journal of Nanjing University of Technology (social science edition), 2004(3):94-96

[6] LiuGuoqing. Reforming Classroom Teaching Method to Explore Optimal Teaching Mode of Probability and Statistics [J]. University Mathematics, 2003, 19(3):27-29 